\title{
Small business complementary medicine: a profile of British therapists and their pathways to practice
}

Gavin J. Andrews and Robin Hammond Faculty of Nursing, University of Toronto, Toronto, Ontario, Canada

\begin{abstract}
During recent years, private sector complementary medicine has grown as a significant provider of health care in the UK, and according to many current definitions, this provision may be classified as primary health care. In the context of a relative paucity of dedicated research investigations, and through a combined questionnaire $(n=426)$ and interview survey $(n=49)$, this paper provides some base-line evidence on the national sector, considers the previous employment of private therapists, their reasons for practicing, the range of modalities practiced and the positives they gain from this form of caring and business ownership. Although some younger therapists had moved straight from their education into private practice, the most common scenario was for middle-aged persons to enter the sector directly from skilled professional jobs and hence had radically changed their careers. Many were formerly employed in caring-related professions such as nursing, social work and teaching. Often therapists had been disillusioned with particular aspects of their former jobs. However, more frequently, they were simply attracted by the therapies themselves, the conceptual paradigms which underpin them and to the different experiences of business ownership and caring practices. Little is known about private complementary medicine, and it is argued that dedicated studies could build the initial evidence presented here, particularly within the rubric of primary health care research.
\end{abstract}

Key words: alternative medicine; complementary medicine; primary health care; private healthcare

\section{Introduction: 'complementary' primary health care?}

The 1978 Alma Alta declaration laid an important philosophical foundation for the development of Primary Health Care (PHC) worldwide, when it defined it as:

Essential health care based on practical, scientifically sound and socially acceptable methods and technology, made universally available to individuals and families in the community through their full participation and at a cost that the community and country can afford to maintain at every stage of their

\footnotetext{
Address for correspondence: Dr Gavin J. Andrews, Faculty of Nursing, University of Toronto, 50 St George Street, Toronto M5S 3H4, Ontario, Canada. Email: g.andrews@utoronto.ca
}

development in the spirit of self-reliance and self-determination. It is the first level of contact with individuals, the family and community with the national health systems bringing health care as close as possible to where people live and work, and constitutes the first element of a continuing care process.

(WHO, UNICEF, 1978: 6, cited in McMurry, 1999: 11)

During the past two decades, definitions of what services constitute PHC have varied and, although perhaps indirectly, many definitions have concentrated on, and have developed particular features of, the above statement. As one editor of this very journal pointed out in its' first issue (Bryar, 2000), most commentators now agree that PHC is 'first contact' care (Shaffer, 1984), often continuous (Starfield, 1994), geographically dis- 
persed amongst communities (Roland and Wilkin, 1996) and is used to maintain personal functioning or for preventing pain, and thus in assisting the maintenance of everyday activities (Sheaft, 1998). Furthermore, McMurry (1999) cites equity, access, empowerment, self-determination and inter-sector collaboration as basic principles of PHC. These elements, we argue, seem to sit well with common forms and features of the private provision of what has become collectively known as 'Complementary Medicine' (CM), 'Alternative Medicine', 'Integrated Medicine' and 'Holistic Medicine', all of which are terms used somewhat interchangeably to describe a diverse range of therapeutic and diagnostic therapies which have developed largely independently from orthodox medicine (OM) (Druss and Rosenheck, 1999). The more popular modalities include acupuncture, chiropractic, osteopathy, massage, hypnotherapy, reflexology, aromatherapy, homeopathy, naturopathy and herbalism, although more than 300 disciplines could be listed if each of the above disciplines were broken-down into all their sub-varieties (Chez et al., 1999). As the following literature review will reveal, they are often first contact, continuous, dispersed and spatially unbounded in provision, and used by consumers for their personal functioning and well-being. However, this said, other definitions of PHC, particularly those which have developed other aspects of the 1978 declaration, are not as potentially inclusive of private CM, indeed they may even be exclusionary in their nature. These develop, and stress, the need for scientific evidence bases, public finance and provision, and full integration into wider health systems (see for example World Health Organization, 1988). This lack of inclusivity is arguably reflective of a wider acceptance debate regarding the regulation and incorporation of $\mathrm{CM}$ into $\mathrm{OM}$ provision. (House of Lords Select Committee on Science and Technology, 2000; Department of Health, 2001). Nevertheless, given the substantial growth in CM provision and use worldwide, we argue here that the time has now come to be more pragmatic, and that because (under many current and accepted definitions) private sector $\mathrm{CM}$ does provide $\mathrm{PHC}$, it deserves serious and dedicated attention within the rubric of PHC research. Various PHC focused studies have now begun to consider that $\mathrm{CM}$ which is well integrated into formal public PHC delivery (see Anderson and Anderson, 1987; Botting and
Cook, 2000; Emanual, 1999; Grenfell et al., 1998; Patterson, 1997; Wharton and Lewith, 1986). Arguably, independent private CM should also be considered by research, even if it is not formally connected to OM provision. Indeed, research has already begun to focus on consumer experiences of the private sector (Andrews, 2002; 2003a; Willison and Andrews, 2004). In this context, and given a relative paucity of research, this paper provides a foundation on which to build the UK evidencebase by presenting some important base-line data on private therapists, their attitudes and their businesses. In no way does it, or can it, cover all potential business and practice issues. Nevertheless, it does consider therapists' previous employment, their reasons for entering the sector, their pathways to practice, the range of modalities practiced and the positives they gain from this form of caring and business ownership. It is argued that this is a solid basis for future research investigating this neglected, yet common, form of private PHC.

\section{Small Business Complementary Medicine}

In the UK provision and use of CM has grown rapidly in recent years. Indeed, Vickers (1994) suggests that between $7 \%$ and $11 \%$ of people visit complementary therapists every year, and Thomas et al. (1995) estimates that $33 \%$ of the population have used some form of $\mathrm{CM}$ at least once in their lives. Meanwhile, the House of Lords Select Committee on Science and Technology (2000), estimates there to be 15 million users of CM nationwide. A small but increasing number of therapists are funded directly by public finance, and work for the National Health Service (NHS) in hospital and community settings. However, the majority of therapists earn a living from direct outof-pocket payments made by privately paying clients (Sharma, 1991; 1995; Zollman and Vickers, 1999). In financial terms, this represents a considerable expenditure. For example, White (1996) estimates the total out-of-pocket spending on private consultations to be between $£ 500$ million and $£ 1000$ million each year, which represents a figure equivalent to between $1.5 \%$ and $3 \%$ of the annual NHS budget. Most private therapists operate independently, either practicing alone or in shared facilities, whilst a smaller number are based 
in general practitioner (GP) surgeries and in health centres. Nationally, the CM sector may enjoy a considerable financial turnover, but the organizational nature of the sector remains one of small private business, essentially a cottage industry (Sharma 1995; Fulder, 1996). The exact number of complementary therapists in the UK remains disputed because not all CM disciplines are regulated and therapists registered. Nevertheless, Zollman and Vickers (1999) estimate the numbers of therapists to have more than trebled from 13,500 in 1981 to 40,000 in 1997. Furthermore, both Fulder (1996), and The House of Lords Select Committee on Science and Technology (2000), estimate there to be approximately 50,000 therapists in the UK. In contrast, there are approximately 32,000 GPs in the UK and arguably complementary therapists can sometimes compete, in market terms, with them to provide certain forms of PHC (Fulder, 1996).

To date, only a small number of research studies have investigated the private provision. Indeed, the main UK studies of therapists consider only their overall numbers and the range of services they offer (Burton, 1977; Fulder and Munro, 1985). The first research, and initial recognition of CM therapists, was commissioned by an industry representative body - The Osteopathy Association of Great Britain (Burton, 1977). This research focuses, rather narrowly, on the structure of osteopathy practices and, in particular, discusses the age and experience of osteopaths. Two cornerstones of industry-wide research on the CM sector, and the catalysts to further investigation, are Fulder and Munro (1985) and Davis (1984). Fulder and Munro (1985), make the first serious attempts to estimate the numbers of private CM therapists in the UK, trends in the growth of $\mathrm{CM}$ provision, the most common forms of $\mathrm{CM}$ and the numbers of GPs practicing CM. Davies (1984) meanwhile, considers a variety of basic business features including the numbers of modalities practiced by individual therapists, the organization of practices, numbers of hours worked and the dedicated education obtained by therapists. A decade passed before further research was published specifically on small business and CM. Sharma (1991; 1995) picked up this mantle and using sociological work theory considers the CM small business sector. Particular foci include the scale and structure of businesses, therapists backgrounds and experience, the factors influencing their decisions to practice, fee levels and relationships with patients. To date, Sharma $(1991$; 1995) remains one of the only detailed studies of therapists, their attitudes, actions and opinions. Methodologically, this study itself has a limited generalisability being restricted to a sample of 34 practices in only one Midlands UK location. However, its depth of focus still makes it a foundational qualitative sociological study. Other studies have focused, more narrowly, on certain features of private practice. Cant and Calnan (1991), for example, consider therapist's opinions of their role in relation to OM and in the full-spectrum of health care available to the general public. The authors found that perceptions varied ranging from alternative to complementary positions, rather depending on the particular modality and the perception of its compatibility with OM. Another important factor highlighted by the research was that therapists regarded the orthodox medical community's perceptions of CM to be at times both ignorant and incorrect. Research which investigates ethical and safety issues is now emerging. Greene (1998), for example, questions the antiageing claims made by some complementary therapists, and Vickers et al. (1998) questions the clinical safety of advice given by 'alternative' health food shops. White et al. (1997) is the latest quantitative study to explore the working practices of CM therapists, concentrating on fee levels and therapists' attitudes towards working within the NHS. The authors found that therapists were willing to work for the NHS but preferred to do this from their own premises. They were slightly less enthusiastic about working in primary care settings and in hospital-based out-patient facilities. The research also highlights that therapists current fee levels may be a little unrealistic given their qualifications, skill levels and likely NHS salaries.

The current research complements a series of papers originating from a Nuffield Foundation funded study. Andrews (2003b) investigates those therapists who had been practicing nurses and their reasons for leaving the British NHS. The research findings highlight a variety of push and pull factors and, importantly, that if given a degree of autonomy and independence, nurse-qualified therapists would seriously consider returning to the NHS in a dual nurse-CM therapist capacity. Andrews et al. (2003) considers the ethical and moral dilemmas in the management and provision of private CM. 
The findings draw attention to the potential tensions between being a career and, in market terms, a profit maker. Highlighted is that therapists rarely claim to base their decisions to discontinue, or to refuse treatment, on financial considerations, and that, in contrast, they often make personal financial sacrifices in order to continue treatments. In the light of the British policy agenda to bring OM and CM closer together, Andrews (2003c, personal communication) considers therapists attitudes towards practicing in the NHS and found many therapists to be generally positive, yet to express concerns, over maintaining respect, autonomy and independence in practice. Andrews (2003d, personal communication) investigates business decisions, plans and aspirations and, by using the petit bourgeoisie as a conceptual framework, considers therapists' wider social and economic position and role. Andrews (2003e, personal communication) takes a novel perspective and considers the use of imagination and memory of places for therapeutic goals and effect. The current study adds to above research in two ways. First, it provides evidence of the industries and professions that therapists came from and why they ended up in practice. Secondly, it provides a profile of their age, gender, and stage in the life course. Arguably, these are issues fundamental to any other consideration of therapists but are issues that are relatively under-researched. Therefore, this is a baseline study which underpins all research on therapists' practice decisions following their market entry.

\section{Research methods}

A combined interview and questionnaire survey was funded by the Nuffield Foundation in 20012002 and was selected as the most appropriate method to sample an appropriate full-range of therapists and modalities whilst maintaining an indepth and sensitive investigation of key issues. The dual approach was not conducted for purposes of methodological triangulation (verification); rather a two-staged approach provided different, and complementary, breadths and depths of foci on broadly the same range of issues.

The questionnaire survey: An initial sample of 1832 private complementary therapists was randomly selected from local telephone directories. It has been noted in other research studies that there is really no foolproof way of discovering the entire range of $\mathrm{CM}$ services either nationally or within particular localities in order to obtain a sample frame. Therefore, sources of information such as libraries, professional organizations and directories have been utilized by researchers (Sharma, 1995). The sample used was constructed from five regional sub-samples located in London, the East Midlands, the south west, the north east and Wales. Regional sub-sampling was undertaken to ensure that the spatial distribution of the sample broadly reflected the uneven spatial distribution of therapists nationally, and in particular, a spatial bias of CM provision towards the south of the country and in certain towns (Fulder, 1996). The comparative sizes of each regional sub-sample therefore mirrored the overall numbers of private therapists advertized in that area. Each regional sub-sample was also stratified so that it contained similar proportions of the different modalities of therapies as found locally. The overall sample represented the majority $(70 \%)$ of all therapists advertized in each region. From the 1832 questionnaires sent by post in July 2001, 426 were successfully returned $(23.25 \%)$, which the authors considered to be a good response for a postal survey. The questionnaire record sheets were purposefully long (eight pages), and semi-structured, allowing the respondents to write their answers in detail. Each questionnaire would have taken the respondent approximately 30 minutes to complete, which given the required commitment, again indicates a good response rate. The number of returned questionnaires $(n=426)$ may be insufficient to elicit nationally generalizable data, though it may give an indication of wider trends. Indeed, the issue of generalizability is complicated because, as suggested, estimates for the number of private $\mathrm{CM}$ therapists vary from 30000 to 60000 in the UK, making the sample somewhere between 0.9 and $1.5 \%$ of the total population. However, when considered with the qualitative data, it combines to present a comprehensive description of therapists, and their backgrounds.

The interview survey: Forty-nine face-to-face interviews were completed with therapists in three study sites based in the south east, the south west and the East Midlands of England. These therapists were also randomly selected from local telephone directories. A personalized letter outlining the aims and objectives of the research was first sent to 
practitioners, and a follow-up telephone call was made to enquire if they would be willing to participate and to arrange an interview time and place. The interview survey was undertaken in order to collect more focused qualitative attitudinal data and investigate certain issues in greater depth. Most of the interviews were conducted at the therapist's clinic, but a minority were conducted in local cafes. Audiotapes were used to record conversations if the therapist felt comfortable with their usage, otherwise detailed record sheets were compiled during and after each interview. Interviews were semi-structured in that they were initially interviewer-led and followed a basic format with predetermined avenues of enquiry. However, the latter part of the interviews were less structured and allowed the interviewee to discuss issues important to them. Each interview took between 50 and 90 minutes to complete, rather depending on how much the interviewee wished to contribute.

Analytical approach: The analytical approach utilized techniques derived from the principles of grounded theory. Indeed, as Charmaz (2000) comments, grounded theory is well established and currently serves at the forefront of qualitative research. The theory was initially presented by Glaser and Strauss (1967), but subsequently it has been refined and a range of associated techniques developed. Therefore, as is the case with many other studies, in a purist sense, it is these derived techniques which are used in the current study, rather than the exact and original documented approach. When using grounded theory and associated techniques, theory evolves during the actual research, and does so through the continuous interplay between analysis and data collection (Strauss and Corbin, 1998). A central feature of this analytical approach is therefore constant comparative analysis (Glaser and Strauss, 1967), and the circular movement between data collection and interpretation, theory development, and back to research. Indeed, incoming data are used to formulate theory, or are meticulously played against existing theory and used to replace, extend, or modify it (Charmaz, 2000). So, in grounded theory, generating theory and doing research are essentially two parts of the same process (Glaser, 1978). In the current study, the analysis initially prioritized and focused on codes and key areas of interest suggested by the initial research questions, and was subsequently directed by the ongoing theory development process. In particular, preliminary analysis of the questionnaire survey, influenced the design and content of the interviews, which in-turn were further developed and refined from each other as they progressed. The quotations below are taken from the interview survey, or from questionnaires where respondents elaborated their answers in depth. The descriptive statistics are taken exclusively from the questionnaire survey. As the data presentation will show, the more openended questions were anaylised to elicit frequency of comment clusters.

\section{Findings}

Of the 426 respondents, $155(36.4 \%)$ were male, and $269(63.1 \%)$ were female $(0.5 \%$ nonresponse). The youngest of the respondents was 25 years old, and the oldest 76 years, the mean age being 46.9 and the standard deviation 10.0. What is therefore immediately striking is the female domination of CM private sector provision and a middle-aged, age profile. Indeed, these findings are supported by Sharma $(1991 ; 1995)$ which found therapists to have a mean age of 42 years and similarly most to be female. Regarding the structure of their private businesses, $45.3 \%$ of therapists claimed to be practicing CM part-time, $48.6 \%$ claimed to be practicing full-time, whilst $2.3 \%$ claimed that they worked 'as much as possible' (3.8\% nonresponse). Reflecting the part-time nature of much private practice, $34.9 \%$ claimed to supplement their income with other forms of paid work and $27.6 \%$ by working in the same types of work that they were involved in prior to their involvement in a CM businesses. However, a common aim of therapists was to develop their businesses and to eventually work exclusively full-time. This is reflected in the infancy of many businesses. Indeed, the respondents had been practicing for between three months and 43 years, the mean length of practice being 10.5 years and the standard deviation 7.9 years. That many businesses were relatively new, reflected the considerable growth in the private sector in the UK during the previous 15 years.

The 426 respondents practiced a total of 801 therapies (Table 1). Although it was most common for therapists to practice one modality of $\mathrm{CM}$ (mode $=1$ ), this was evidently not always the case 
Table 1 Types of therapies offered

\begin{tabular}{|c|c|c|c|}
\hline Modality & Frequency & $\begin{array}{l}\text { Percentage } \\
\text { of } \\
\text { modalities }\end{array}$ & $\begin{array}{l}\text { Percentage } \\
\text { of } \\
\text { therapists }\end{array}$ \\
\hline Massage & 75 & 9.4 & 17.6 \\
\hline Homeopathy & 75 & 9.4 & 17.6 \\
\hline Reflexology & 66 & 8.2 & 15.5 \\
\hline Psychotherapy & 65 & 8.1 & 15.3 \\
\hline Osteopathy & 64 & 8.0 & 15.0 \\
\hline Hypnotherapy & 55 & 6.9 & 12.9 \\
\hline Aromatherapy & 52 & 6.5 & 12.2 \\
\hline Acupuncture & 45 & 5.6 & 10.6 \\
\hline Herbal therapy & 36 & 4.5 & 8.5 \\
\hline Chiropractic & 34 & 4.2 & 8.0 \\
\hline Reiki & 34 & 4.2 & 8.0 \\
\hline Counseling & 30 & 3.7 & 7.0 \\
\hline Shiatsu & 20 & 2.5 & 4.7 \\
\hline Alexander & 19 & 2.4 & 4.5 \\
\hline \multicolumn{4}{|l|}{ Technique } \\
\hline Nutritional advice & 17 & 2.1 & 4.0 \\
\hline Naturopathy & 13 & 1.6 & 3.1 \\
\hline Natural healing & 13 & 1.6 & 3.1 \\
\hline Allergy advice & 9 & 1.1 & 2.1 \\
\hline Stress & 7 & 0.9 & 1.6 \\
\hline \multicolumn{4}{|l|}{ management } \\
\hline Yoga & 5 & 0.6 & 1.2 \\
\hline Kinesiology & 4 & 0.5 & 0.9 \\
\hline Acupressure & 3 & 0.4 & 0.7 \\
\hline Life Coaching & 3 & 0.4 & 0.7 \\
\hline Others & 57 & 7.1 & 13.3 \\
\hline Total & 801 & 100.0 & - \\
\hline
\end{tabular}

and many therapists specialized in more than one. The number of therapies practiced by individuals ranged between one and eight, the mean number being 1.9. These findings support Davies (1984) who found over $50 \%$ of therapists to practice more than two therapies and $25 \%$ more than three.

The relative proportions of different therapies differs from the findings of previous surveys, which questioned consumers not providers. Zollman and Vickers (1999) report that Which (1986), Mori (1989) and Thomas et al. (1993) all list acupuncture as the most common CM modality followed by chiropractic, herbal medicine, homeopathy and osteopathy. Meanwhile, Ernst and White (2000), found herbal medicine to be most the common form of CM, followed by aromatherapy, homeopathy, acupuncture, reflexology, massage, osteopathy and chiropractic. In contrast, and as Table 1 identifies, the current study found acupuncture to be 8th most common, chiropractic 10th, herbal medicine 9th, osteopathy 5th and aromatherapy 7th. Massage was most common (practiced by almost one in five therapists), a frequency equalled by homeopathy, then closely followed by reflexology (3rd), psychotherapy (4th) and osteopathy (5th). However, an important point to be considered is that the above user surveys calculate frequencies of use and not frequencies of provision as in the current study. Therefore, the data from user and provider surveys may not be either directly comparable or indeed contradictory. More generally, what was striking was the extremely wide-range of therapies practiced, especially considering that certain categories could include many variants and sub-varieties. The category 'Massage', for example, included at least six variations, some specific to particular parts of the body, some with specific technical procedures and some with origins in specific geographical regions or countries. Examples include, Swedish massage, deep massage, and therapeutic massage. Indeed, during the analysis a particular and challenging task was identifying and categorizing sub-varieties of CM such was the diversity, specificity and obscurity of many responses.

As Table 2 identifies, therapists' previous forms of employment are varied. Furthermore a total of

Table 2 Therapists' previous employment types

\begin{tabular}{lrr}
\hline $\begin{array}{l}\text { Previous employment } \\
\text { type }\end{array}$ & Frequency & Percentage \\
\hline Skilled professionals (private & 78 & \\
sector) & & 16.0 \\
Nursing & 63 & 13.0 \\
Education/teaching & 57 & 11.8 \\
None (student of CM) & 52 & 10.8 \\
Secretarial/clerical & 39 & 8.0 \\
Service sector & 34 & 7.0 \\
Arts-related & 33 & 6.8 \\
Social Care & 27 & 5.6 \\
Social Work & 18 & 3.7 \\
Local Government/civil service & 11 & 2.3 \\
Other NHS & 10 & 2.0 \\
Unskilled manual & 10 & 2.0 \\
Housewife & 9 & 1.9 \\
Private business & 9 & 1.9 \\
Skilled manual & 7 & 1.4 \\
Military & 2 & 0.4 \\
Unemployed & 2 & 0.4 \\
Retired & 1 & 0.2 \\
Missing (nonresponses) & 23 & 4.7 \\
Total & 485 & 100.0 \\
\hline & & \\
\hline
\end{tabular}


485 responses indicate that respondents could have been employed in more than one job directly prior to their practicing $\mathrm{CM}$. The most common category is 'skilled professional' (78), although this is perhaps slightly deceptive as a discrete category because it contains a wide-range of former job types including for example, chief engineers, architects, designers, bankers, and public relations managers. These types of jobs, along with some other categories, do though suggest a slightly middleclass, or at least affluent, profile for therapists and in many cases a radical change in job types.

The largest single job category was nursing (63). For this group, a very specific set of push factors from the NHS can be identified which are largely associated with wider structural and experiential issues such as the long hours worked, the job pressures created by constant policy and management changes, changes in job roles and frustrations that $\mathrm{CM}$ was not adequately integrated into their former jobs. Related pull factors may also be identified. Some are caring related, such as preferences for the way CM deals with patients and their welfare; the closer interpersonal relationships between patients and therapists and being able to help patients to a greater degree. As suggested, this specific group of nurse-therapists is considered in a dedicated paper in relation to current nursing recruitment and retention debates (Andrews, 2003b).

The other caring-related professions of teaching, social care and social work together accounted for almost one-quarter (21\%) of all previous professions. The former teachers and social workers were not as explicit about their push factors and dissatisfactions with their former jobs in comparison to the nurses. However, given that the questionnaire was generalized and designed to capture the opinions of all professions, and that the researchers had no previous indication that they would arise in substantial numbers, there may well be underlying dissatisfactions that were missed in the current study and thus therapists with these professional backgrounds, and the issues surrounding their changes in careers, may be worthy of dedicated research investigation. Indeed, given recruitment and retention problems also facing these particular professions, the movement of teachers and social workers into $\mathrm{CM}$ is highlighted as an important area for future research.

A relatively small proportion of therapists (52,
$10.8 \%$ ) entered the sector straight from education as their first career. Often these therapists were younger and had undertaken either a full or part time course as part of their training directly after school, and sometimes within higher and further education institutions. Of the 52 therapists who entered practice straight from their education, 31 were osteopaths. Indeed, these 31 represent almost one-half of all the 64 osteopaths in the questionnaire survey. The first destination career tendency of osteopaths reflects osteopathy's increasingly professional status and the longer periods of often full-time education required to qualify and practice. It may be speculated that, in future, as a wider range of $\mathrm{CM}$ modalities gradually become more professionalized, and their training standardized and expanded, the proportions of these first destination career therapists may increase. However, at present, they remain a relatively small minority. Interestingly, very few therapists $(1.9 \%)$ had owned a business prior to CM practice, yet small business ownership is a necessary bi-product of CM practice, and indeed all of the respondents in the current study implicitly ran some form of small private business. Indeed, in light of this lack of experience, business decisions and attitudes are highlighted as important areas for future research investigation.

As Table 3 identifies, over one-third of therapists (158) stated that they were originally motivated to enter practice after experiencing successful treatment either directly themselves or indirectly by their family and friends. Two suggested:

I received hypnotherapy myself in 1995 coupled with divorce. It was such a wonderful experience which allowed me to deal with all the emotional problems at that time. It has had a profound effect on my life ever since.

For my own children, complementary medicine had proven to be safer and more effective for all common childhood complaints. This was also the case for me and my partner.

For these two therapists, their experience of CM was at least enlightening, for others it was even shocking. Their experiences formed the foundation of a belief which eventually grew so strong that it became a career choice. Just under one-third of therapists (141) stated that they gradually 
Table 3 Motivations and circumstances for entering CM

\begin{tabular}{|c|c|c|c|}
\hline Motivation & $\begin{array}{l}\text { Frequency } \\
\text { of comment }\end{array}$ & $\begin{array}{l}\text { Percentage } \\
\text { of comments }\end{array}$ & $\begin{array}{l}\text { Percentage } \\
\text { of therapists }\end{array}$ \\
\hline Witnessed/experienced the success of CM & 158 & 17.5 & 37.1 \\
\hline Developed a personal interest in therapy & 141 & 15.6 & 33.1 \\
\hline Wanted to help people & 126 & 14.0 & 29.6 \\
\hline Unhappy with orthodox medicine & 99 & 11.0 & 23.2 \\
\hline Unhappy with previous job & 55 & 6.1 & 12.9 \\
\hline The independence and flexibility of self-employment & 52 & 5.8 & 12.2 \\
\hline To seek greater job-satisfaction & 36 & 4.0 & 8.5 \\
\hline Re-evaluation of goals in life (often after crisis) & 33 & 3.7 & 7.7 \\
\hline A mentor/therapist encouraged them & 30 & 3.3 & 7.0 \\
\hline Previous job ended/had to leave previous job & 23 & 2.5 & 5.4 \\
\hline Interpersonal (wanted more contact with people) & 20 & 2.2 & 4.7 \\
\hline A unique opportunity arose & 17 & 1.9 & 4.0 \\
\hline For financial benefit & 16 & 1.8 & 3.8 \\
\hline For spiritual reasons & 15 & 1.7 & 3.5 \\
\hline To increase personal skills & 13 & 1.4 & 3.1 \\
\hline Other & 68 & 7.5 & 16.1 \\
\hline Total & 902 & 100.0 & - \\
\hline
\end{tabular}

developed a personal interest in CM over time, and that this interest eventually led on to their practice. Two suggested:

I began to be interested in the way emotions and spirituality affect physical health.

I was interested in self-healing and then in healing others. I had an intellectual interest in Chinese medicine, anatomy and physiology and how energy works.

Another popular motivation for practice was wanting to help people (126). Indeed, this was a common and very basic caring-related motivation and often something that therapists thought that their former occupations lacked. The final quotation below demonstrates the potential for this motivation to be very personal in nature, and how it can be directly related to family and friends:

I had found that these systems of healing could result in tremendous alleviation of mental, emotional and physical systems so wanted others to receive these benefits.

Osteopathy is hands-on, applied anatomy with a sound logical basis and is very effective. It was what I was looking for after my A levels to enable me to work in a 'fixing' capacity anywhere in the world.
My father died of cancer. I knew he would get ill before he died, he lost the will to live. No one was treating that and what I do now does. It makes me sad to see people suffer and glad to help.

Others (99) stated an unhappiness with OM, either in its financing, organizational structure or efficacy. For some, this unhappiness originated from direct and first-hand negative experiences, for others it came from more general observations of $\mathrm{OM}$, and in particular the perceived market connections between OM and pharmaceutical companies. In either scenario, by entering the private sector for CM, therapists had chosen to do something about their unhappiness:

After a period of ill-health, I thought that there had to be a better way. Politically I was scandalized by the lack of choice and the ignorance in orthodoxy. As a biologist, homeopathy made intuitive sense to me.

A realization that orthodox medicine is dominated by pharmaceutical companies aiming to make enormous profits. They exert massive influence on doctors with hard-sell propaganda and hidden bribes ignoring more effective, side-effect free, but less profitable treatments.

I had a longstanding interest in hypnosis and 
complementary therapy and a dislike of blanket prescriptions of drugs for all conditions by mainstream medicine.

As Table 3 identifies, other reasons for market entry included dissatisfaction with a previous job (55) and seeking greater job-satisfaction (36). Together these two work-related push factors accounted for just over $10 \%$ of responses. Wanting to be self employed (52), a re-evaluation of life's goals (33) and being encouraged by a mentor (30), were also cited, whilst relatively few (16) cited financial motivations. Given that over 900 reasons were cited by the 426 therapists, and the mixed reasons highlighted, many respondents evidently had multiple motivations for entering CM. Indeed, the interviews often revealed complex and very individualized stories about therapists particular pathways to practice. What is undeniable however is that these changes in mid-career and life course were not only highly and complexly motivated, they were often radical and substantial changes. As a consequence, respondents' day-to-day experiences of work life have changed considerably.

The survey also investigated the positives that therapists gained from CM. As Table 4 identifies, well over one-half of all respondents (243) cited greater 'everyday' satisfaction with their jobs. One commented:

Connecting with the mysteries of life and living. I'm fascinated with life's process and always think wow, amazing. Extraordinary things happen and they do frequently.
Related to the caring motivation cited earlier for entry into the $\mathrm{CM}$ sector, over one-half of therapists (226) cited being able to help people and make a difference to their health and well-being as positive features of their jobs. In this respect, it seems that for many, their hopes and needs had been met. Three respondents commented:

I get a great sense of achievement and also a profound sense of privilege at being allowed to be with people at crucial moments of change and revelation in their lives.

The joy of seeing people get better and become happier. It is quite common for peoples lives to change dramatically for the better after treatment.

I enjoy working in a caring environment, helping people feel better about themselves.

Importantly, the above gains of 'everyday satisfaction' and 'helping people' accounted for over $60 \%$ of all responses. Other types of responses accounted for much smaller proportions. Sixty-two respondents, for example, cited interpersonal factors and enjoying close contact with people:

Joy in giving and receiving, connecting with people in a full way; emotionally, mentally, spiritually and physically and thus connection is kept alive on a personal level.

I find it fascinating and you can always learn from people however young they are.

Table 4 Satisfactions and rewards gained from practice

\begin{tabular}{|c|c|c|c|}
\hline Satisfaction/reward & $\begin{array}{l}\text { Frequency } \\
\text { of comment }\end{array}$ & $\begin{array}{l}\text { Percentage } \\
\text { of comments }\end{array}$ & $\begin{array}{l}\text { Percentage } \\
\text { of therapists }\end{array}$ \\
\hline Greater everyday job satisfaction & 243 & 31.2 & 57.0 \\
\hline Ability to help people & 226 & 30.0 & 53.1 \\
\hline Interpersonal relationships formed & 62 & 8.0 & 14.6 \\
\hline Independence/autonomy/flexibility & 55 & 7.1 & 12.9 \\
\hline Personal development/skills development & 49 & 6.3 & 11.5 \\
\hline Interest/stimulating & 35 & 4.5 & 8.2 \\
\hline Financial & 30 & 3.9 & 7.0 \\
\hline Challenging & 20 & 2.6 & 4.7 \\
\hline Spiritual & 10 & 1.3 & 2.3 \\
\hline Ethical/moral & 8 & 1.0 & 1.9 \\
\hline Less stress & 6 & 0.8 & 1.4 \\
\hline Other & 36 & 4.6 & 8.5 \\
\hline Total & 780 & 100.0 & - \\
\hline
\end{tabular}


Others cited the independence and flexibility of their job (55). Indeed, this reflects that, for many, a CM practice was their first self-owned private business and this, in itself, was an attractive feature of their working lives. Two respondents commented:

I can have an independent view, flexibility and more time with patients and I'm able to adjust my hours to suit myself.

I've the freedom to work with my own ideas, make my own decisions without the constraints of the NHS.

Interestingly, as with motivations, very few respondents cited financial rewards as an important feature of practice (30). Evidently, as with reasons for market entry, income was not a prime motivating factor (at least admitted). This is understandable given the context of the large proportion of part-time practice and given the professional jobs that many therapists had given up. Interviews also highlighted that each therapist had a very personalized story to tell. Many provided an example of an individual patient case when elaborating. One suggested:

She use to come in and she looked lost. I've seen her confidence gradually grow and she seems like a different person. Now, I know its my job but just imagine how good that makes me feel. When the evidence is right in front of you, you know that you're doing a good thing.

However, as the total amount of comments (780) and the following quotation both suggest, quite often, respondents had a combination of gains:

It's a good way to work with people and help people improve their lives. Its fascinating work, and very rewarding, satisfying and challenging. I enjoy working with people and interacting at a deep and meaningful level.

\section{Conclusion}

In the context of a relative paucity of dedicated research investigation, the paper highlights some broad trends in therapists and their pathways to practice, together with providing some detailed attitudinal data on their motivations and practice experiences. Although many males are therapists, the sector is female dominated. Therapists are a wide-range of ages but most are middle aged. They work a mixture of full and part-time hours, but many work part-time hours and supplement their income with other forms of work. The majority of businesses are relatively new, reflecting growth in the sector during the past fifteen years. Manual therapies, such as massage and reflexology, are the most common modalities, but many therapists practice more than one modality. Complementary medicine was often a second career for therapists, who entered the sector from a variety of former occupations. The most common group were skilled professionals, however, this category was extremely varied. Many therapists came from caring-related professions such as nursing, teaching and social work, and in general there was a middleclass dominated profile. A small proportion of therapists were practicing as a first career and came straight from their education. This group was dominated by osteopaths who generally required longer and full-time periods of training in order to qualify. Therapists were motivated to enter practice by a combination of push and pull factors which often related to being unhappy in their previous job, witnessing the success of $\mathrm{CM}$ and wanting to care for people. Their gains from practice were equally varied, ranging from greater everyday job satisfaction to being able to help people, the interpersonal relationships they formed and being able to be flexible. Notably, pure business and financial features, were rarely cited for both original motivations and personal gains.

There is evidently a lot more to be discovered about private CM and therapists, and this study provides some base-line data on which to build future research investigations. In particular, the study lays a basis for the dedicated investigation of business and business attitudes including structural aspects such as business plans, marketing, expenditures and investments and experiential aspects such as stress, motivations and aspirations. One obvious line of inquiry is to investigate individual modalities of CM which may differ in their regulation, practices and connections with other forms of OM. Indeed, as a baseline survey, the current study purposefully took a very broad perspective on all forms of CM, but different modalities require more sensitive and individualized investigation. 
More generally, the research demonstrates that providers of a range of private nontraditional PHC are entering the market from equally nontraditional career and professional backgrounds. These are a diverse set of people, with a diverse set of motivations, providing a diverse range of health care. However, in terms of volume, they are effectively providing the majority of $\mathrm{PHC}$ in the $\mathrm{UK}$ and arguably in the developed world, more so than even GPs. The argument and research agenda is clear, and our point is simple; that the range and depth of research on CM should mirror this fact. Currently the literature on $\mathrm{CM}$ provision is growing, but extremely slowly, and from a very small base. Researching CM is undoubtedly a trans-disciplinary social science research endeavor and one to which given the first-contact and dispersed nature of much provision, those interested in PHC could meaningfully contribute.

\section{Acknowledgements}

I would like to thank the Nuffield Foundation for funding the research and James Andrews, Trine Hanberg for their assistance with organizing the questionnaire survey, and all the therapists who gave their time to be involved.

\section{References}

Anderson, E. and Anderson, P. 1987: General practitioners and alternative medicine. Journal of the Royal Society of Practitioners 37, 52-55.

Andrews, G.J. 2002: Complementary medicine and older people: service use and user empowerment. Ageing and Society 22, 343-68.

Andrews, G.J. 2003a: Placing the consumption of private complementary medicine: everyday geographies of older people's use. Health and Place 9, 337-49.

Andrews, G.J. 2003b: Nurses who left the NHS to practice private complementary medicine: Why did they leave? Would they return? Journal of Advanced Nursing 41(4), 1-13.

Andrews, G.J., Peters, E. and Hammond, R. 2003: Receiving money for medicine: some tensions and resolutions for community-based private complementary therapists? Health and Social Care in the Community 11(2), 155-67.

Botting, D. and Cook, R. 2000: Complementary Medicine: knowledge, use and attitudes of doctors. Complementary Therapies in Nursing and Midwifery 6(1), 41-47.

Bryar, R. 2000: Primary health care: does it defy definition? Primary Health Care: research and development 1(1), 1-2.
Burton, P. 1977: A work-study of the Osteopathic Association of Great Britain. Part 1: the structure of practices. London: Osteopathic Association of Great Britain.

Cant, S. and Calnan, M. 1991: On the margins of the medical marketplace? An exploratory study of alternative practitioners' perceptions. Sociology of Health and Illness 13, 34-51.

Charmaz, K. 2000: Grounded theory: objectivist and constructivist methods. In Denzin, N., and Lincoln, Y., editors, Handbook of qualitative research. London: Sage, 1161-72.

Chez, R., Jonas, W. and Eisenberg, D. 1999: The physician and complementary and alternative medicine. In Jonas, W. and Levin, J., editors, Essentials of complementary and alternative medicine. New York: Williams and Wilkins, 21-36.

Davies, P. 1984: Report on trends in complementary medicine. London: ICM.

Department of Health. 2001: Government response to the House of Lords Select Committee on Science and Technology's Report on Complementary and Alternative Medicine. London: HMSO.

Druss, B.G. and Rosenheck, R.A. 1999: Association between use of unconventional therapies and conventional medical services. Journal of the American Medical Association 282(7), 651-56.

Emanual, J. 1999: Will the GP commissioner role make a difference? Exploratory findings from a pilot project offering complementary therapy to people with musculo-skeletal problems. Complementary Therapies in Medicine 7(3), 170-74.

Ernst, E. and White, A. 2000: The BBC survey of complementary medicine use in the UK. Complementary Therapies in Medicine 8, 32-36.

Fulder, S. 1996: The handbook of alternative and complementary medicine. Oxford: Oxford University Press.

Fulder, S. and Monro, R. 1985: complementary medicine in the United Kingdom: patients, practitioners and consultants. Lancet 2, 542-45.

Glaser, B.G. 1978: Theoretical sensitivity. Mill Valley, California: Sociology Press.

Glaser, B.G. and Strauss, A.L. 1967: The discovery of grounded theory: strategies for qualitative research. Chicago: Aldine.

Greene, J. 1998: Melatonin for the masses. Anti-aging entrepreneurs peddle therapies that promise to cheat the clock. Hospital Health Network, 72(22), 32-4.

Grenfell, A. Patel, N. and Robinson, N. 1998. Complementary therapy: general practitioners referral and patients use in an urban multi-ethnic area. Complementary Therapies in Medicine 6(3), 127-32.

House of Lords Select Committee on Science and Technology. 2000: Complementary and Alternative Medicine. House of Lords paper 123, November.

McMurry, A. 1999: Community health and wellness: a socioecological approach. London: Mosley.

MORI (Market and Opinion Research International). 1989: Research on Alternative Medicine. London: MORI.

Paterson, C. 1997: Complementary practitioners as part of the primary health care team: consulting patterns, patient characteristics and patient outcomes. Family Practitioner 14(15), 347.

Roland, M. and Wilkin, D. 1996: Rationale for moving towards a primary care-led NHS. In Roland, M. and Wilkin, D., editors, 
What is the future for a primary care-led NHS. National Primary Care Research and Development Centre. Abingdon: Radcliffe Medical Press, 5-12.

Shaffer, R. 1984: Beyond the dispensary. Nairobi: African Medical and Research Foundation.

Sharma, U. 1991: Complementary practitioners in a midlands locality. Complementary Medical Research, 5, 12-16.

Sharma, U. 1995: Complementary Medicine Today: practitioners and patients. London: Routledge.

Sheaft, R. 1998: What is 'primary' about primary health care? Health Care Analysis 6(4), 330-40.

Starfield, B. 1994: Is primary health care essential? Lancet 344, 1126-33.

Strauss, A. and Corbin, J. 1998: Grounded theory methodology: an overview. In Denzin, N. and Lincoln, Y., editors, Strategies of qualitative inquiry. London: Sage, 158-84.

Thomas, K., Fall, M., Nicholl, J. and Williams, B. 1993: Methodological study to investigate the feasibility of conducting a population-based survey of the use of complementary health care. London: Research Council for Complementary Medicine.

Thomas, K., Fall, M., Parry, G. and Nichol, J. 1995: National survey of access to complementary health care via general practice: report of Department of Health. Sheffield: SCHARR, University of Sheffield.

Vickers, A.J. 1994: Use of complementary therapies (letter). British Medical Journal, 309, 1161.
Vickers, A.J, Rees, R.W. and Robin, A. 1998. Advice given by health food shops. Is it clinically safe? Journal of the Royal College of Physicians 32(5), 26-28.

Wharton, R. and Lewith, G. 1986: Complementary medicine and the general practitioner. British Medical Journal 292, 1498515.

Which. 1986: Magic or medicine? October 1986, 443-47.

White, A. 1996: Do complementary therapists offer value for money? In Ernst, E., editor, Complementary medicine: an objective appraisal. Oxford: Butterworth Heinemann, 89-106.

White, A., Resch, K. and Ernst, E. 1997: A survey of complementary practitioners' fees, practice and attitudes to working within the National Health Service. Complementary Therapies in Medicine, 5, 210-14.

Willison, K. and Andrews, G.J. 2004: Complementary medicine and older people: past research and future directions. Complementary Therapies in Nursing and Midwifery, in press.

World Health Organization, UNICEF (United Nations Children's Fund). 1978: Primary health care. Geneva: World Health Organization.

World Health Organization. 1988: From the Alma-Ata to the year 2000: reflections at the midpoint. Geneva: World Health Organization.

Zollman, C. and Vickers, A. 1999: The ABC of complementary medicine: users and practitioners of complementary medicine. British Medical Journal, 319, 836-38. 